ACKNOWLEDGEMENTS

This paper is based on a talk given at a meeting of the Social and Community Psychiatry Section in February 1982, but represents the work and ideas of the Working Party. We are indebted to Mr Gil Robertson for Tables II and III.

REFERENCES

Department of Health and Social Securtry (1975) Better Services for the Mentally Ill. Cmnd 6233. London: HMSO.
Hirsch, S. R., Platt, S., Knights, A. \& Weyman, A. (1979) Shortening hospital stay for psychiatric care: Effect on patients and their families. British Medical Journal, $i$, 442-46.

ROBERTSON, G. (1981) The provision of in-patient facilities for the mentally ill: A paper to assist the NHS planners. Operational Research Section, DHSS.

\title{
The DHSS Mental Illness Policy Paper: A Personal View
}

\author{
JoHn ReEd, Community Psychiatry Research Unit, Hackney Hospital, London
}

In November 1982, a conference on the provision of comprehensive, district based, psychiatric services was organized by the Community Psychiatry Research Unit of St Bartholomew's Hospital Medical College. At this conference, Lord Trefgarne, Parliamentary Under Secretary of State at the DHSS, reaffirmed the Department's policy of creating local district psychiatric services and closing those mental illness hospitals which are not well placed to provide a local service.

Dr Douglas Bennett, giving a final summary from the Chair, felt that the conference had established that the debate about the comprehensive district based services was finally over and that the need for a new pattern of service was accepted; the issues now were not whether, but how best to make the change. The point had come at which the strategies could begin to be implemented.

The new Mental Illness Policy Paper, Mental Illness: Policies for Prevention, Treatment, Rehabilitation and Care, * issued by the DHSS, must be considered against this background.

It is introduced as a "note, prepared by DHSS Mental Health division, in consultation with professional colleagues as being intended to meet a request from Regions for a brief consolidated note on the mental illness policies advocated by the Department in various circulars and notes. It does not describe any new policies, nor does it seek to specify good practice or to prescribe an ideal arrangement for a psychiatric service.'

What it does do, and the DHSS is to be congratulated on this, is to present in brief compass the main provisions and policy decisions that have developed in relation to the development and organization of mental health service policy since Better Services for the Mentally Ill in 1975. While it does not act as a substitute for reading the original documents, it is certainly useful for all those involved in planning and in delivering psychiatric services to have available an up-to-date synopsis of policy and proposals.

The present move towards district based psychiatric services is conveniently considered from the time of publication of Better Services for the Mentally Ill in 1975 which envisaged 'local district network' as the new pattern of

- Limited copies are available from the College. service. In this pattern the DGH psychiatric unit was meant to serve not only as an in-patient department but as 'a centre providing facilities for treatments on both a day and inpatient basis and as a base from which the specialist therapeutic teams provided advice and consultation outside the hospital.' At that time the guidance relating to joint health and local authority planning was consigned to four paragraphs on the penultimate page of the text and discussion of the role of mental hospitals in the transition period was relegated to an appendix. As it turned out these two issues are the ones which have proved to be the greatest stumbling blocks to the development of a full range of local services for mental illness.

Subsequently, the DHSS has produced several papers; in 1976 came Priorities for Health and Personal Social Services in England which reiterated the Better Services strategy and suggested the priorities for a capital programme. The Way Ahead, in 1977, expanded the discussion based on Priorities, but was seen by many advocates of more locally based services to be less enthusiastic than previous documents.

A more optimistic view was promoted again in Care in Action (1981). In this the mentally ill are identified as one of the priority groups for improved services. The need for joint planning and collaboration is emphasized: 'Health and local authorities have a statutory duty to co-operate to secure the health and welfare of the population.' Care in Action identified three urgent tasks; one, the creation of locally based services; two, the provision of a full range of services for the elderly severely mentally infirm; and three, making arrangements over the next 10 years for the closure of mental hospitals which are not well placed to fit into a district service.

Care in the Community (1981) explored possible ways in which the patients and resources might be transferred from NHS services to alternative locally based services.

These DHSS publications form a part basis of the present document. Other publications that have had important influence in development of the policy include the DHSSsponsored symposium 'Policy for Action: A symposium on the planning of a comprehensive District psychiatric service', held in 1973. Much in the new paper is, as is to be expected, 
a restatement of existing policies, but it is possible to identify within the document certain changes of emphasis and understanding which have great importance for the development of psychiatric services. For instance, in comparison with Better Services, discussion about the importance of taking into account the contribution of social services, education, housing, employment and all other voluntary and statutory services is promoted from the last few pages to the second paragraph of the present document. This emphasis on the essential interdependence of the Health Service and all the other voluntary and statutory services cannot be too warmly accepted. It will, however, still be necessary to reach some clearer and more effective method for Joint Care Planning than exists today. Glennester (1982), reviewing eight years of statutory collaboration, indicates only very limited success at the expense of considerable time-'Local Authority Officers are grateful for the extra funds joint financing may have brought, but are none too happy with the form it takes or its long term implications for their budgets, while Health Officers are none too sure about the value for money that they are getting.' Glennester identified three main reasons for the difficulties that have been found: (1) the absence of a long term review of future resource levels, and service development objectives; (2) the new joint planning machinery has been asked to do the impossible - to make up a legislative inadequacy; (3) the whole perception of the way in which organizations and professional people work together was unrealistically naive. If this very necessary collaboration between Health and other services is to be developed, then clearer ways of proceeeding with the Joint Planning must be found. Despite the emphasis on the need for joint consultation and planning, further information about how to make planning work within a District is extremely limited. It is not a reasonable assumption that the presence of a Mental Health Planning Team and a Joint Planning Team will necessarily result in any coherent policy being pursued.

The emphasis on the shaping of services to fit the specific needs of each District is to be welcomed, and the suggested 'range' of norms for beds is likely to lead to more careful planning of provisions.

It is perhaps not made sufficiently clear in relation to 'norms' that deficiencies in one element of service, e.g. day hospital places, cannot be made good by over-provision in other areas, such as in-patient beds. An essential part of the planning of a comprehensive district service is the consideration of the balance that is needed between elements of the service- beds, day places, hostels with varying levels of supervision-and the network which links one with another making transition easier for patients.

The reiteration of the fact that the hospital should be seen as part of the community and a community resource centre, rather than as an entity separate from the District it serves, is very welcome. Donald Dick has pointed to the anomaly that 95 per cent of the people with psychiatric problems are outside the hospital, whilst 95 per cent of the people dealing specifically with these problems are inside the hospital. While the policy document touches on this problem and rightly points out that psychiatrists and other professionals are increasingly involved in the patient's home setting and in health centres, it seems likely that a stronger lead may be necessary in order to persuade people to change long established habits of work.

Many of the sections of the paper will be taken as acceptable by most people working in a locally based service, and the statements of the policy have, as the document says at the beginning, all been proposed before. However, as a compendium of policies restated together, there are some areas that I think do give cause for concern.

The problems of making joint planning effective have already been mentioned. Other points touched on in the paper that caused me concern were the fleeting references made to the needs for clinical psychologists, occupational and other therapists. The role of these staff, and indeed all staff involved in the prevention or management of social disability in the chronically ill (but not necessarily chronically hospitalized), appears undervalued.

In dealing with the long term chronically mentally ill, the suggestion of there being little practical value in distinguishing between 'new long stay' and 'old long stay' is to be welcomed. Such distinctions often obscure the special needs of the chronically psychiatrically ill which require special facilities, pitched at different levels of competence. It is good to see a hint of understanding that the number of people who stay in hospital for a long period of time depends not only on the number of hospital beds that are available but also the amount of alternative properly supported accommodation available outside of the hospital. The reference to the study on hospital hostels by Wykes and Wing (1982) is a pertinent one particularly since the establishment of the hospital hostel shortly afterwards generated the provision of a wider range of supported accommodation for 'graduates' from the hostel.

The paper has some areas that are barely touched on. No mention is made in the policy paper of the major problem of how far present policies are preventing any unnecessary accumulation of new long-stay patients. This is a problem of prevention of disability, requiring urgent attention. Barely mentioned is the very pressing need to start retraining existing staff to work in district based services as mental illness hospital based services are run down. Although many of the skills useful in a large institution would be helpful in a district based service, there are many new things to be learnt. Health Authorities need to be encouraged to arrange programmes for retraining of all types of staff at an early stage in the development of district based services, without this staff will not be best able to join in either the planning or the running of a locally based service.

The question of finance is touched on as set out in Care in the Community, with transfer of funds between health districts or between the health service and local authorities as patients are transferred. Although this may well be the way 
in which final financial accommodations are reached, it would be quite unrealistic to expect a district to be able to build up the complex network of services that is needed to provide a local service without adequate interim funding. Savings by closing large hospitals will not be possible until the local services have been developed, and interim funding for a period of, say, three to five years to enable a district to develop local facilities will be needed before money can become available by transfer of resources. Fallure of interim funding is likely to be a major reason for failure to develop local services. The provision of adequate interim funding needs a clearer statement of policy from the DHSS.

One final area which is not mentioned in the policy paper is the need to develop locally in each district an effective data base. Present statistics are inadequate in content and available too slowly to allow good locally based planning, which must be an integral part of a locally based service. An effective data base can also comprise a computerized service register which is an important tool in the effective management of patients in a district based service. Such services, being usually much more diffuse than a service based on a large psychiatric hospital, need to have a records system that is capable of keeping in close touch with patients despite a wide range of contact points.

All in all, this policy paper is required reading for all involved in the development and delivery of services to the mentally ill. It should be read in conjunction with Donald Dick's paper, Components of a Comprehensive Psychiatric Service. It is brief, to the point and helpful though perhaps over-simplifying the problem in some areas. That is a better fault than making an Everest out of a Ben Nevis.

\section{ACKNOWLEDGEMENT}

Parts of this article are based on a paper written for the King's Fund by my colleague, Gillian Lomas.

\section{REFERENCES}

Glennester, H. (1982) Barter and bargains. Health and Social Service Journal, 26 June, pp 771-73.

Wing, J. K. (ed) (1982) Long-Term Community Care: Experience in a London Borough. Psychological Medicine, Monograph Supplement 2. Cambridge University Press.

\section{Review}

Mental Ilness in Old Age: Meeting the Challenge (Policy Studies in Ageing: No 1). By Alison Norman. London: Centre for Policy on Ageing. 1982. Pp 135. £5.75.

Positive, purposeful and creative, this is a likeable little book addressing the 'how' to do of things and thus cutting short the heartache that sometimes taints caring texts on old age. Alison Norman's timely review will be welcomed as source material to be used alongside Donald Dick's mobilization of awareness through the efforts of the Health Advisory Service and their publication The Rising Tide.

Hitherto media and political interest in confused or depressed old people has been sporadic and often seemed most pleased by sensations: savage neglect, brutal exploitation or harrowed despair. Ms Norman, as a committed outsider, has devoted her considerable energies and talents to travelling, listening and now reporting on the state of play as it is day by day and week by week across this patchwork island. Patchwork it certainly is and is reflected to be. Yet the best counterpanes are worked to an overall design to achieve their best effect.

We have here a wonderful catalogue of individual and group enterprises, actions, views and some things approaching religious conviction. The advantages to be derived from allowing some social workers, nurses and others to specialize in work with mentally ill old people are well argued. They can generate interest and confidence in colleagues who can turn to them for help, advice and direction without handing over all potential customers. Anxieties that undesirable 'elitism' will be fostered by such specialization and refining of skills is largely misplaced. A gentle, but firm, finger touches on the mixed merits of blurring roles in domiciliary support teams that employ a range of personnel. Common sense allied with the highest professional skills is required to maintain efficient nets of care in the unstructured time and space of 'the community'. The potential of day care, intermittent in-patient care, and the possibility of warmth and interest (even) in long-stay settings or residential alternatives are sympathetically explored. Reading and rereading these passages will stimulate comparison with other local and wellloved enthusiasms. References to easily available articles and documents add to the usefulness of this publication.

The arena has lain all but empty for years. The vigorous babble that now wells up includes much that is good or very good and some that is basically crackpot. It is important that professionals and volunteers are guided away from aberrant courses to speed the psychiatry of old age towards respectability and its proper place in the service and educational fabric of this country. Ms Norman provides many useful hints on design.

DAVID JOLLEY

Withington Hospital

SUSAN Hodgson

West Didsbury, Manchester 